\title{
Semiocide: An introduction to semiotics of destruction of the meaningful
}

\author{
Mehmet Emir Uslu'
}

\begin{abstract}
The aim of this article is to expand on the concept of semiocide which, in broad terms, is the destruction of signs and semiosis. Taking its point of departure from Ivar Puura's article on the concept, this essay attempts to find conceptual parallels and historical examples of the term, expanding its range through a critique of its original conception. Departing from the initial conservatism of Puura's definition, the article will argue for a more diverse understanding of the term, suggesting a view that positions semiocide not just as a descriptor for lamentable losses, but also as a potential avenue for emancipatory praxis, whereby established, hegemonic and oppressive meanings can be undermined and new possibilities of representation and identity explored.
\end{abstract}

Keywords: semiocide; memory; conflict; forgetting; cultural studies; cultural destruction

\section{Introduction}

Past meaning and experiences, whether of achievements or failures, shape individuals and societies, forming their characters and the narratives of their identities and self-descriptions. As these collected experiences and narratives, characters - both individual and social - are created and sustained, providing validation, security and a sense of identity. But these experiences are not purely accumulative: they do not consist of seamless and lossless deposits of the past, cached in perfection and available to an immaculate recall. Even on its own terms and without any explicit intervention to it, the past is accessible only by active means whereby it is constantly re-interpreted and re-evaluated in accordance with the specific form of society, the particular values that it espouses or discourages, its particular aims to which it aspires or consequences it aims to avoid. It thus consists of a selection, an abstraction from a lived experience as a result of which certain elements, narratives and experiences are retrievable, while others remain inaccessible. Moreover,

1 Department of Semiotics, University of Tartu. E-mail: m.emir.uslu@gmail.com. 
regardless of its field of inquiry, (e.g. into ideas of nation, religion, class, race or gender, et cetera), interpretations of the accessible past are not uninterrupted or unperturbed. Clashes and conflicts, either sporadically or systematically, test them and disrupt them resulting more often than not in a modified condition distinct from its prior form.

Cultures, as they evolve and transform, for various reasons re-evaluate or abandon prior conventions that constituted them, reforming existing conventions or discarding surplus information within the culture. In Genealogy of Morals Nietzsche (2009[1887]: 42) notes the wilful suspension of memory, a refusal to "ingest" any further, as a peaceful, if temporary, pause as the body adjusts and regulates itself (Nietzsche 2009: 42) within its confines without the incursion of further intake. Extraneous pressures such as repression or humiliation can also cause abandonment or disappearance of particular forms of experience, for reasons ranging from resolution of attrition between conflicting parties to imposition of shame from non-group quarters Connerton (2008: 59). The borders of cultural inventories in this sense are reminiscent of how Conan Doyle's Sherlock Holmes describes the organisational principle of his own mind: an attic room that a wise man would furnish only with what is useful to him as opposed to any trivia. Though this strictly utilitarian view of one's mental toolkit has changed drastically even within Doyle's own canon to a more eclectic reservoir of "an omnivorous reader with a strangely retentive memory for trifles" (Doyle 2011: 241), the abandonment of seemingly irrelevant or undesirable knowledge is by no means an uncommon occurrence. Connerton's premise that forgetting is more than simply a deficiency of memory is an important claim. In his concise and self-admittedly inexhaustive taxonomy of forgetting, Connerton (2008: 62) argues that forgetting is more than simply the inability of recall, but at times a purposeful deletion or planned obsolescence of particular memories, geared towards not only institutions of authoritarian politics of memory, such as censorship (in a top-down disallowance of memory), but also constitutive regimes whereby prior conflicts are resolved through mutual abandonment of the past, drawing a line underneath a particular disagreement so that new relations could be built unhindered by unresolved frictions. One of the most interesting proposals in Connerton's list is dubbed "humiliated silence", specifically deriving from the post-1945 German society where, as Connerton argues, the moral burden and the shame of the Second World War weighed so heavily on the public that lamentation of the German public of their own misfortunes became muted to the extent of being silent (Connerton 2008: 67). As opposed to the commonplace understanding of forgetfulness, Connerton underlines the decision to not remember instead of an inability to recall as a potent feature of social cohesion; a means of erasure to 
readjust and cohere a totality, as well as ensuring, albeit at times authoritarian, compliance.

To the variety of such polyvalent destruction, this article attempts to add one more - the term 'semiocide', first coined by palaeontologist Ivar Puura (19612012) to describe a "situation where signs and stories that are significant for someone are destroyed because of someone else's malevolence or carelessness, thereby stealing a part of the former's identity" (Puura 2013: 152). Puura's coinage draws on individual as well as collective memory, recognition of the passage of time and of the past, and the connection between humans and their surroundings as a reciprocal relation that affirms and sustains both.

Material and abstract objects play an equal part in this conceptualization, as the loss of either, whether it is sacred sites and memorials in the former category, or languages, concepts or ideas in the latter, are victims in the process of this loss. Furthermore, Puura also notes homesickness, a distinct yearning for an earlier state of being, with specific signs, surrounding and relations. In its relation to nostalgia, which used to be diagnosed as homesickness, the sense of this disconnect and yearning for another time rather than another space, bears a similar tendency to attachment to specific, subjective and highly individual memories. Neurologist Endel Tulving calls these episodic memories (Tulving 1993: 67), one of the two types of memory that take the centre stage in his writing: semantic memory, concerned with factual and non-context-dependent memories; and episodic memory, consisting of autobiographical and context-dependent ones.

As has been noted later, "all living organisms are connected to their environment through semiotic relations accumulated in time" (Maran 2013: 147), but humans are distinguished from other animals by our capacity to perceive time not only as a recurrence of particular conditions such as day and night, or the passage of the seasons, but in a way in which we could contemplate our pasts, personal or collective, and plan our futures. This ability to travel mentally back in time, chronesthesia (Tulving 2002), allows us to re-experience our pasts, re-establishing our bonds with our earlier memories which constitute our identities. It is this awareness of our past and its potential consequences to our present and our capacity to conceive of our future, as well as our social capacities, that make semiocide an important and, at times, dangerous term.

Human capacity to impact their environment drastically on a potentially planetary level opens up an expansive space that is already being claimed and studied under the concept of "ecocide" (Broswimmer 2002: 9; Crist 2013: 47), whereby human action causes unprecedented harm through a tendency of infinite growth in a finite world. While it is not exclusive to our period, ecological destruction has certainly been exacerbated in the late modern era. Previously comparatively small 
and geographically limited activities of human societies can now not only impact, but also structurally alter entire ecosystems. Events on a planetary scale, such as anthropogenic climate change and mass extinctions of species are accompanied by their consequences in the daily life of an average individual: contamination of basic needs of life - arable soil, potable water or clean air. Pollution on the basic life-sustaining processes inflict further harm down the line to the sensory capacities and altering related meaning-making process. Roland Posner (2000: 291-294) gives a rudimentary set of examples of material and semiotic pollution, where the consequences of the former type are detectable and impactful on the latter. Following the communicative function schema by Jakobson (1960: 353), Posner (2000: 295) provides a list of potential pollutants of each of elements therein, e.g. pollution of the code via a "muddle" in the correlation of the semantic and syntactic spaces.

As Maran (2003: 148) underlines, the pervasive presence of this phenomenon in culture and society embodies a "dark side" of semiotics that has so far been unremarked on or unexplored. It is the aim of this essay to elucidate the ways and means via which this particular "negative" relation manifests, as well as exploring in what ways it may be "amended".

\section{Precedents and formulations}

In its current form, semiocide is more akin to a general, albeit vague concept. It does not possess a diverse taxonomy that could respond to various conditions where disappearance of semiotic relations may occur. As such, returning to this seminal definition and expanding from its premises will yield more fruitful prospects.

The reasoning behind this operation stems from the premise that, in its current form, the definition proposes a limited and very particular angle on semiocide, which effectively precludes any intimation that it could be used in a way other than destruction of a preferable prior order. Although the current definition matches such conditions, the possibilities of semiocide exceed what appears to be an account that is conservational and conservative, due to the implicit underestimation of possibilities within the term, as well as due to the implicit focus on the ecological concerns regarding the protection of natural environment, wildlife or, more importantly, a particular way of social life in a given period, to which one desires to return (or that one prefers to an alternative).

Certainly, situations where a significant object or relation is being destroyed are not limited only to ecological relationships - such situations occupy a considerable 
place in culture as well: relics, monuments and places of symbolic importance throughout history have been enclosed, removed, defaced or outright destroyed for reasons beyond simple material necessity: the destruction of Palmyra's Lion of Al-lāt, Temples of Baalshamin and of Elahbel are only a few recent incidents of such action (Shaheen, Swann, Levett $2015^{2}$ ). The investiture of meaning to an object beyond its material use persists in many cultures, either as the creation of fetishes symbolizing particular roles and function of individuals after particular animals or crystallization of historical narratives and related values in religious objects that require a specific spatial and/or temporal prearrangement. Moreover, such objects, as the examples of saintly relics demonstrate, impart a sense of authority, legitimacy and respect to the spaces that harbour them as was the case of medieval monasteries that, through their possession of such relics, became destinations for pilgrimages.

The primary argument here is that the phrasing of this fundamental definition of semiocide is biased towards this assumed dichotomy, whereby accidental acts are paired with not only purposeful, but also "malevolent" acts, thereby imposing a somewhat loaded term unto an epistemological distinction: there would presumably be contemplation of certain moral codes. Let us recapitulate Puura's definition: "I understand semiocide to be a situation in which signs and stories that are significant for someone are destroyed because of someone else's malevolence or carelessness, thereby stealing a part of the former's identity" (Puura 2013: 152-153 [2002: 24-25]; emphasis added).

This definition is not erroneous as such, but it is nevertheless extremely limiting. If confined to these specific conditions, destruction of signs and stories through a particular agency would restrict semiocide almost exclusively to a retrospective mode: looking back in yearning to an inaccessible past, all signs of which have been severed. However, Puura's unspecificity regarding what he means by "sign" makes it difficult to assess his concerns: his references to indigenous peoples' signscapes consisting of their native flora (Puura 2013: 151) tend towards semiotic affordances; the environment "affording" the inhabitants to employ environmental elements as sign objects (Maran: 2013:147; Gibson: 1986:127). These elements build our relationship to our surroundings and our particular history with these. Puura's further reference to language death regarding the history of his native Estonia further reinforces the idea that he views signs as persistent elements of memory-building. Semiocide, in this framing, would be a conceptual

2 Shaheen, Karem; Swann, Glenn; Levett, Cath 2015. Palmyra - what the world has lost. The Guardian 5 October). Online: https://www.theguardian.com/science/ng-inetractive/2015/ oct705/palmyra-what-the world-has lost (retrieved on 23 October 2020). 
tool of qualified lamentation, ascribing a sense of historical mourning to semiotic relations that do not survive malevolence and carelessness. To unpack this problem of confined categories, we can begin with the examination of the types of semiocide proposed by Puura, identify their interrelation and argue in favour of a less constrained model.

The first component in this dichotomy is one in which a sign or story is destroyed through carelessness, which corresponds to acts in which the actors have limited or no knowledge of the consequences. Lack of awareness of the semioticity of those in the ambit of the act, or simply a lack of knowledge of their presence at all, occupy this half of the proposition. Potentially, the destruction may be averted by expanding and increasing one's knowledge in the given field or context (Maran 2013: 148). However, this would concern knowledge, rather than a value judgment of given knowledge being either right or wrong. As opposed to its "malevolent" counterpart, this kind of semiocide does not target its victim as such, but, rather, the latter is caught up in a related but unrecognized process.

Accidental/careless semiocide requires unpacking due to its containing of differing undercurrents, which adhere to the general category (of lack of intentionality), yet are distinct as concerns detail. We can argue that there are two conditions nestled in this leg of Puura's dichotomy: (1) the destructive act is not necessarily targeting its eventual victim, and (2) the agent is not aware of either the existence or the semioticity of the victim.

Still, there is no precondition for these to be simultaneously present in each and every case, leading to possibilities in which the semiocidal agents are aware of possible victims of their act without a consideration for the latter's survival. This condition would be better defined as one of indifference - as mentioned above, occupying a state of knowing, but not caring. Although there is no case of absolute lack of knowledge as to the consequences, we still would not be stepping over to the dimension of malevolence, as purposeful destruction of the victims is not intended either.

It should be noted that despite its innocuous appearance, accidental/careless semiocide is variable in its underlying categories and does not merely consist in mishaps borne out of ignorance. It is possible to surmise asymmetries between the instigator and the victim of such acts of semiocide, which may explain mechanics of both the unawareness and the indifference between the parties. Inequalities in not only power, but also range, hegemony or resilience between the parties may constitute modes of indifference. The actual or presumed grandeur of novel modes of thought and their implications may be, and has been, interpreted as having substantial consequences, the acquisition of which was considered worthy regardless of their cost, often paid at the expense of the systems and societies they have replaced. 
This may be witnessed in the historical developments of some human societies. One such substantial shift can be viewed in the European Enlightenment project, in its castigation of its preceding modes of thought as irrational and irreconcilable with the domination of nature by human reason, deprived of what Bruno Latour (1993: 35) described as "hybrids of old" seeing them as nothing but "illegitimate mixtures that they [Enlightenment luminaries] had to purify by separating natural mechanisms from human passions, interests or ignorance". Perfectibility of the human condition through reason thus dispensed with the traditional ideas of truth and knowledge. The presumed indivisibility of Man (Gurevich 1992: 297) was replaced by a conception whereby Man not only stood outside Nature, but also above it, in a position of domination (Pálsson 1996: 65). Even the shift from 'the individual' as an indivisible continuity to the emphasis on discontinuity and distinction signifies a radical change of perspective (Williams 1984: 161-165).

This shift is explanatory of the agency of humans upon their surroundings: erasure of God as the final arbiter of truth and His replacement by humanity, in Nietzsche's famous dictum "God is dead and we have killed him", not only points at the culprit in this deicide, but also indicates who is now in charge. Humanity, or in fact "mankind" in the spirit of its predominantly gendered self-description, stood atop the ordering of the world. Gísli Pálsson outlines this new order, whereby he draws attention to the cynegetic themes that pervade it. His description of the "orientalist" mode of human-environmental relations emphasizes that the use of a vocabulary drawing heavily on hunting, as well as not-so-subtle references of sexual domination reveal the viewpoint of the modern society to its surroundings (Pálsson 1996: 68). In what Pálsson describes as "negative reciprocity' as the defining quality of such orientalist relations, mankind dispossessed nature, without a thought to the potential consequences of such dispossession.

In retrospect, the ruthlessness of such dispossession is limited neither to the period nor to the untamed wilderness that the modern man exploits. Karl Marx's description of capitalism, whereby its leading actors "stripped of its halo every occupation hitherto honoured and looked up with reverent awe", and reduced them all to paid labourers (Marx, Engels 1998[1848]: 38) points at a not-sodissimilar process: if not wholly annihilated, a previously significant system of signs, consisting of specific relations, is nevertheless subjugated under a new order in which the previous relations are no longer recognizable or equally efficient. By transforming and reducing all relations, and indeed all individuals, to commodities and traders of exchange value, the capitalist mode of production levels all earlier distinctions down to the one of "free" trade. Indeed, as a historical theory, Marxism is premised on the idea that conflicts, specifically class struggles of groups delineated by property ownership, are fought across the ages and 
irreversibly transform their societies. The modernist inclination for grand narratives, vast overarching processes with expansive explanatory capacity tends to possess this tendency to dwarf and at times suffocate comparatively minor meanings without necessarily intending to do so.

Arguably, one can still glean instances of malevolence in these processes. Such overarching transformations perhaps inevitably come at a cost both to the environment and/or those inhabiting it. Whether in terms of ignorance or of indifference, semiocide exacts a toll irrespective of its instigator's intent and this lack of clear intention on the part of the actor should not blind us to its negative consequences.

Still, on the basis of theoretization, whereby we attempt to build the tools through which we approach and examine these relations, distinctions of intention nevertheless need to be made: the distinctions made by Ivar Puura as well as the amendments and modifications proposed in this essay attempt to sift through the convoluted relations in which various modes of semiocide are often intertwined. This does not mean that these modes are mutually exclusive solely by the dint of one mode's dominance. After all, as also argued in this paper, semiocide does not necessarily entail total destruction of signs, but also their suspension. Interplays of power between multiple parties often see a previously dominant sign system being driven underground, marginalized or in terms of Juri Lotman's semiosphere, pushed to the periphery where determination of the rules and conventions of the semiotic space is nil or minimal, so that it loses the ability to exert influence on the space it used to occupy. This particular angle, concerned with more of a graduated alteration rather than a wholesale disappearance, would allow us to view meanings in altered contexts.

Accidental/careless semiocide is a common occurrence, and can often be encountered in scenarios where humans and nature are in a protracted confrontation. In view of the unviability of the nature/culture divide, we can specify these situations as those in which the modernist view of humanity is distinct and superior to nature, viewing it as a mixture of tabula rasa which could be inscribed at will and a seemingly infinite larder from which humans can replenish themselves without consideration to restock. Nature as man's playground, which has been a dominant narrative through modernity, conceals the considerable harm the latter inflicts upon the former. The conquest of nature, bending nature's will to the needs and demands of society, has disrupted and destroyed many naturally occurring semiotic relations, from migratory paths of birds (Forman, Alexander 1998) to entire local ecological formations (Knight 1996).

As was briefly noted above, the accidental mode is often conflated with what we may best call 'indifference' - ignoring what is known or learned, rather than not knowing at all. The distinction we make or are expected to make, if we adhere to 
Puura's dichotomy, is that the acts of semiocide are either careless and their implications are not fully understood, or they are indeed known and subsequent action despite this knowledge makes the action purposefully malevolent. However, the case of indifference straddles a middle ground. The implications are by no means unknown, therefore not necessarily subordinate to "accident", yet neither do they explicitly aim for destruction, but are ambivalent instead: so long as the desired outcome is achieved, it is immaterial if a complication is resolved or destroyed.
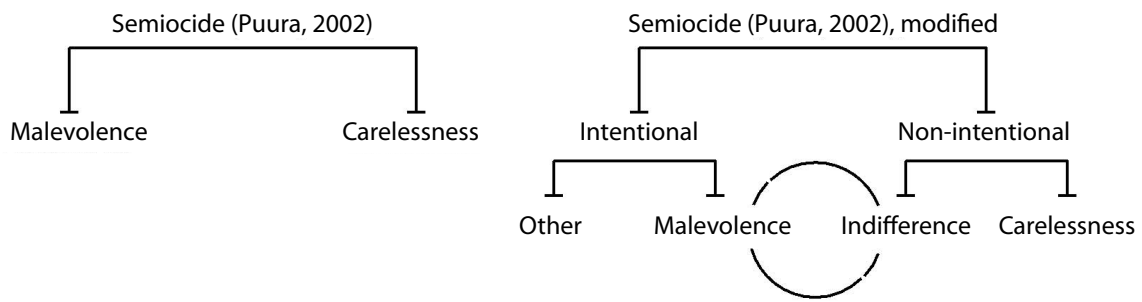

Figure 1. Ivar Puura's original model (left), modified to embrace proposed alterations to account for indifference (right). Despite malevolence and indifference being in different categories regarding their intentions, the knowledge of the consequences of the actions creates a relationship between them. The asterisked 'other' category loosely accounts for currently unformulated events of semiocide, in which purposeful acts with intent to regulate a crisis (as intimated by Connerton's 'prescriptive forgetting') or to emancipate (by undermining and/or destroying representations of an oppressive system).

The component of malevolence that is opposite to accident or carelessness in this dichotomy poses certain difficulties, chief amongst which is the aforementioned "limiting" effect that this framing poses. Briefly, this purports that an act that destroys a sign or story is by definition malevolent if enacted on purpose. In the context of nature preservation, this may be the case. A purposeful act against natural habitats, especially in view of the destructive, extractionist policies regarding natural resources in the age of a global climate crisis, can be rightfully interpreted as such. However, a framing where there is a categorical concomitance of ethical (as mentioned above, due to a specifically loaded adjective) and epistemological considerations precludes semiocide from accounting of instances where the status quo ante is harmful and oppressive in itself. The initial dichotomy of carelessness and malevolence, cleaving semiocide into actions undertaken in presumed ignorance, is concerned with the knowledge of consequences (or the lack thereof). Yet the counterpart to this category not only hints at knowledge of consequences, but frames them as "malevolent", conjuring up an ethical dimension which could have been assumed, but not necessarily so forcefully denoted. 
Puura's model adequately covers conditions in which there is a state of normality the maintenance and upholding of which is desired, and in which alterations to this state are detrimental.

It is the circumstances under which the established system features destructive and harmful elements where his definition falters: if such conditions themselves, rather than acts of semiocide against them, are stealing parts of identities of its occupants, the current iteration of the term is inadequate, as it would brand acts of self-preservation by the oppressed as malicious. In this sense it becomes necessary to formulate situations where the baseline being examined is subjected to semiocide, arguably by those therein who are at a disadvantage.

As such, rather than erasing Puura's distinction between careless/accidental and malevolent semiocide, his taxonomy could be restructured, so that malevolence still was accounted for, but not as the sole alternative to accidentality Furthermore, it would also become untangled from conflations with actions that aim to negate harmful sign processes with a view to emancipate: as noted above, we should make allowances for situations in which the destructive aspects of a status quo are the object of semiocide and actions against them, albeit potentially intentional, should be subject to analysis without being categorized as malevolence. Actions taken in order to preserve one's freedom and one's agency to act in accordance with one's will, as outlined by Isaiah Berlin (1969), either individual or collective, can be considered under this rubric.

First of all, this would allow the relinquishing of the impositions produced by the equivalence of cognisant and purposeful agency with cognisant, purposeful and harm-seeking agency. Secondly, it would allow for an understanding of acts of semiocide as they occur in structural social and cultural change, in which signs and stories pertaining to the demolished system can still be accounted for. This argument brings about two interlinked questions: firstly, if semiocide is concerned with the destruction of signs and systems of signs and, assuming this destructive operation is successful, how can one speak of or even contemplate a non-existent entity? Secondly, if the operation is not successful and the targeted sign or sign system remains intact, can this be grasped within semiocide, as the signs were not destroyed? The former contingency renders the apprehension impossible, since it has no object, while the latter makes it irrelevant since the operation is a dud.

One way to approach this paradox is through analogies: semiocide is not the sole concept that grapples with systematic destruction of a particular group or type. While some of these other concepts deal with the destruction and killing of singular entities (matricide, patricide, vaticide, deicide), others grapple with either plural entities, groups (genocide) or abstractions, as the concept of linguicide demonstrates. Initially, we can thus decide as to whether we position 
ourselves with the former, singular grouping or the latter, plural one. The zerosum approach, whereby the value of semiocide is determined by whether it is a total success in eradicating a sign or a failure (and irrelevance) for not being able to efface a sign, would doubtlessly simplify its workings at the expense of nontotal yet significant shifts incurred as a result. Obviously, the possibility of a sign system being so thoroughly eradicated that it cannot be conjured back is a real one, but what is equally obvious is that this is only one contingency amongst many others, in which we can argue that either there are traces that can be followed or the sign system absorbs the damage, alters and adapts itself accordingly, while also registering its loss. After all, various acts of violence, such as pogroms and genocides cause staggering damage to their victims, whose loss is undeniable though not so total as to efface entire social groups.

\section{Amendments and qualifications}

If we are concerned with the range and breadth of what is meant by "destruction of signs and stories", we could examine the other element in Puura's definition that merits further attention: the predicate 'destroy' which determines the nature and the character of the action taken to a sign or a story. To begin with, it is possible to argue that a sign (or a sign vehicle/bearer) need not be physically destroyed to fulfil the conditions to which Puura refers. Although destruction of the physical, material being of a sign, that is, the tangible embodiment that bears a meaning, can occur and has occurred, the possibilities of semiotic "destruction" range far beyond these conditions. Physical interference of sign relations extends far further than mere material destruction; removal of significant objects or monuments, or enclosure of significant spaces, repurposing of parts or whole of a structure also inflict damage to sign relations without necessarily causing physical harm. Semiocide is also concerned with the damage to or destruction of sign relation, not only of the sign bearers themselves. As such, although destruction of tangible bodies pertains to the concept, they are not limited to it. This angle would allow us to examine issues such as gentrification in case of which public spaces are restructured in view of the social standing of their inhabitants.

There is an interplay between the material and non-material aspects of meaning-making processes that needs to be taken into consideration: while a material object that is significant may remain intact, it may be rendered inaccessible through shifting the physical or conventional boundaries surrounding it. The enclosure of common land in 17th-century Britain, where the land occupied by tenant farmers and rented out by absentee landlords was reappropriated as 
private property (and resulted in the eviction of the local populace), provides an example of the continued physical presence accompanied by the introduction of concomitant conventional boundaries. Conversely, material displacement accompanied by a continued signification in absentia sets out an interesting antinomy, of which the Hippodrome, located in İstanbul's old city, provides an example. Dating back to the third century AD, the location was designed to hold chariot races, and featured four bronze-gilded equine statues. As the city was sacked by the Fourth Crusade, the statues were pillaged and later taken to St Mark's Basilica in Venice. Regardless of its disuse and dispossession, the location still remained, although its meaning was constructed through absences.

In his seminal work The Past Is A Foreign Country, historian and geographer David Lowenthal provides an expansive section on moving historically significant objects, ranging from small and portable ones such as nails, paintings or medals to large and cumbersome ones such as portals of the Bank of India or Trajan's Column (the latter were bisected for easy viewing indoors) (Lowenthal 1985: 282-283). The removal of artefacts Lowenthal documents can occur in various contexts, such as claiming war booties, thefts or accidents, and while some objects are eventually returned to their original locations, others are retained and often collected in museums and galleries. Some of the removals have been motivated by material greed, such as raiding of tombs while others have occurred in an attempt to imbue an otherwise prosaic locale (Lowenthal 1985: 285) with a historical touch, not to mention the colonial endeavours to collect the artifacts and monuments of Antiquity, ostensibly for their protection and in view of the posterity at the expense of their meanings to their original locales and their inhabitants.. The continuing debate on the restitution of the Elgin Marbles provides a highprofile example of this. While individual motives for such protection are debated on grounds of cultural imperialism, removal of artefacts that would otherwise be lost is nevertheless a conceivable problem for conservationists and archaeologists. Considering the severance of the spatial bonds of such artefacts in the event of removal, the dilemma of losing something significant in its entirety or salvaging disembodied, decontextualized parts can arise.

Amongst other historical narratives a great deal of colonial history may be examined in this light. These are stories and constructions that stem from a particular lack, a particular connection built and viewed through an absence. Not only inanimate objects such as monuments or cultural artefacts, but also living entities, no matter if it is the land or the people that are severed from it through slavery, exile or migration, may produce a vacuum in the social and cultural texture. Although continuous emergence and articulation of new forms maintain activity, these are arguably distinct from those processes that are built through a 
presence. The latter constitutes new and organic relations, whereas the former can only rely on static, pre-established conventions. It is not the case, for instance, that the land from which its traditional inhabitants have been removed, is no longer present. The land is obviously still there, but either through a spatial separation or one that is imposed through a legal or social convention it is separated from its inhabitants and the prior sign relations have ceased.

Articulation and thematization of such absences may vary from grievances regarding injustices and wrongs committed by others to forms of self-inflicted modes such as martyrdom, exile or self-exile, the latter of which Raymond Williams (1984: 108) defines as "[one] that could, if he chose, live at ease in his society, but to do so would deny his personal reality". It is an identity assumed due to the lack of a desired form of society, leading the individual to abandon it in favour of an alienation or a self-abstraction until the desired conditions are present. The adjustment of boundaries between different cultures or within a single given culture, offers a conceptual tool to define the occurrences of "access" as outlined above. Juri Lotman (2001: 131) describes the boundary as a membrane separating that which is "ours" as opposed to "theirs"; a distinction between the "cultured, safe, organised" and the "other, hostile, dangerous and chaotic". Spatial conceptualization is present in this framework, but more importantly the adjustability, whereby semiotic dynamism renders previously marginal languages into complex systems with rules and grammars of their own (Lotman 2001: 134). Two important passages in Lotman"s study of the boundary deal with the peripheral volatility of the semiosphere (Lotman 2001: 136), and introduction/reintroduction of texts and individuals that were previously unknown and overlooked, but then came into prominence due to metalingual shifts. Both these arguments, in their specific points, will be of help in the setting up of a mechanism whereby disconnection of the sign relations through cross-boundary displacements could be formulated.

But the hottest spots for semioticizing processes are the boundaries of the semiosphere. The notion of the boundary is an ambivalent one: it both separates and unites. It is always the boundary of something and so belongs to both frontier cultures, to both contiguous semiospheres. The boundary is bilingual and polylingual. The boundary is a mechanism for translating texts of an alien semiotics into 'our' language, it is the place where what is 'external' is transformed into what is 'internal', it is a filtering membrane which so transforms foreign texts that they become part of the semiosphere's internal semiotics while still retaining their own characteristics. (Lotman 2001: 136) 
As Lotman notes earlier, semiospheres attain their fully-fledged form following their stage of self-description where they lay down their own grammars, laws and codes. This structuring allows the system stability, albeit at the expense of indeterminacy that lends it flexibility and dynamic potential (Lotman 2001: 128). Lotman (2000: 128) continues by arguing that "the stage of self-description is a necessary response to the threat of too much diversity within the semiosphere" which he suggests may cost the system its unity and definition. This implies a tradeoff, a gain in rigidity, uniformity and a stability at the expense of a more diverse inventory - a prospect also observed in the erasure of vernacular languages in the process of linguistic standardization (Hobsbawm 1996: 1073). The boundaries lie where differences collide and interplay, where the centre exerts its convention as the convention of the whole sphere, whereas the periphery pushes back and makes claims for self-assertion.

Secondly, and more crucially for the boundary as a possible element in semiocide, a further passage explicates how, due to changes in the metalanguage of the semiosphere, previously omitted text and artists may (re)surface:

When the metalingual structure of the semiosphere changes we get studies of 'unknown' and 'forgotten' writers, similarly when stereotyped-images change we get works such as 'the unknown Dostoyevsky' or 'Goethe as he really was', which give their readers to understand that up to now they did not know the real Dostoyevsky or Goethe and that the hour of the true understanding has now arrived. (Lotman 2001: 137)

It is possible to argue that metalingual shifts in a semiosphere go both ways and are exclusive as well inclusive; just as new or hitherto unremarked forms are introduced, formerly included forms may as well be removed from the system whether through unwritten conventions of fashion or rigid enforcement of legislation. Again, the case here is signs and texts being pushed out through the boundary, whereby they are made "other", and rendered to the position of an outsider no longer acceptable or familiar with the inside of the semiotic space. These are obviously not confined only to literature or arts, but tend to encompass a wide range of social behaviours that were, at some point or other, commonplace and generally accepted. Through lengthy self-interrogation or sudden and spasmodic processes of more radical reformations, their structure rejects certain previous conventions; although exact motives and causes may require thorough ad hoc analysis, general taxonomies such as that proposed for language death by Lyle Campbell and Martha Muntzel (1989) provide a reliable set of conditions that can, albeit tentatively, be applied to the present case. 
The typology the authors propose consists of the four general categories: sudden death, where an event such as war, famine, genocide or natural disaster wipes out an entire community with little to no survivors - the essential point here is not necessarily the kind of the adversity, but its abruptness. The consequences should be so sudden, as it were, that the language either loses the entirety of its users, or reduces them to such a minimal number that the language can longer reproduce itself in future generations. Secondly, there is the radical language death, described as rapid, albeit not so much so as the sudden category; it is language death whereby a community shifts to another, more dominant language due to an immediate necessity, such as persecution, threats and similar aggressions. Forced assimilation processes, imposing linguistic, social and cultural uniformity tend to instigate such radical shifts (Hobsbawm 1996: 1073). Thirdly, the authors describe gradual language death, which is arguably the most widespread phenomenon. According to this process, relatively more longitudinal circumstances, for example lack of economic opportunitites or consequences of detrimental environmental conditions such as, but not limited to, climate change, motivate younger generations to seek their fortunes elsewhere, thereby gradually depriving their native language of new speakers and reducing the pool of active speakers to elderly language users. The final category is that of the bottom-to-top language death, whereby a language undergoes a change so that it no longer operates as the language of daily use, but maintains itself as the code of a higher, specialized order.

As can be discerned, causes of these negative and subtractive processes stem from extraneous sources; it is not the case that a language or a sign system in general suffers from a debilitation caused by its own workings. As was suggested by Lotman (2001), once a sign system establishes its stability its volatility or indeterminacy disappears. This, however, does not preclude the incursion of outside influences or attempts of destabilization that exist outside its range of operation. Furthermore, the relations between the core and the periphery can be elucidated and expanded in consideration of the character and tendencies of the various elements at play.

\section{Boundary as an element of semiocide}

In the Lotmanian semiosphere, we can see a system in which a (mostly) static centre encounters an "alien" entity, be it a text or a collection of texts, which is translated through the filtering of the boundary. We have so far argued that, in the spirit of the abovementioned "dark side" of semiotics, an inverted mirror image appears whereby the introductions of signs into a system also imply the opposite: 
the "destruction" of signs by pushing them outwards, out of the system or systems. What Lotman (2011: 128) argues to be "the highest form and final act of a semiotic system's structural organisation", self-description, imparts codified laws and customs that come at the expense of the system's indeterminacy, which lend it its flexibility and capacity for dynamic development.

Lotman fleshes out the semiosphere's structure through a multiplicity of subordinate spaces; its various components change, develop and alter at different paces. So long as they adhere to the general and unifying principle of its centre, or as long as they do not contradict it fundamentally, the heterogeneity is maintained. A distant but reminiscent parallel to this model can be found in the works of Raymond Williams (2005: 38). Viewing the formulations of the Marxian base and superstructure as a strictly deterministic and unilateral model, Williams criticizes the assumption that economic conditions wholly prefigure and are projected unto cultural production (Williams 2005: 32). For Williams, the primary point of departure is not the object, 'superstructure' nor the subject, 'base', but the predicate, 'determine'. In his work of cultural lexicography, Williams traces the meaning of 'determine' to its Latin roots, as "that which sets bounds" (Williams 1988: 98). His understanding of 'to determine' echoes this etymology, loosening the tight and prefigurative hold of the word in favour of "setting limits and exerting pressures" (Williams 2005: 32).

The limits, defining the foremost edges of what he describes as a dominant and effective culture, are regulated by the specific mechanisms and purposes of this central entity. It is left vague, perhaps intentionally, what a dominant and effective culture actually is. Williams asserts that it exists and has existed in every culture in any period, signifying the central node that exerts its will across its range. So far, the similarities with the Lotmanian semiosphere run somewhat visible: both authors view culture as an interconnected system of components, whose formations are determined (in the sense used in the paragraph above) in relation to a central node; 'centre' in Lotman's thesis, 'dominant culture' in that of Williams. In his developmental arguments, Lotman describes the centre as the author of the rules and regulations, while Williams also touches upon culture as a complex and expansive space in which a myriad elements, such as the arts, literature, laws, and religions, amongst others, exist in a highly complex interrelation with one another, in relation to the dominant culture.

Williams' divergence, however, lies in his inquiry as to the motives and purposes of these pressures being exerted and limits being drawn and defined. Though a great complex structure with distinct but interrelated components is closer to our lived experience of culture in society than economically determined causality, he argues that configurations and, most importantly, selections within 
a culture need to follow and adhere to the needs and desires, as well as recognizability in terms of the dominant culture.

Thus we have to recognise the alternative meanings and values, the alternative opinions and attitudes, even some alternative senses of the world, which can be accommodated within a particular effective and dominant culture. This has been under-emphasised in our notions of a superstructure, and even in some notions of hegemony. And the under-emphasis opens the way for retreat to an indifferent complexity. In the practice of politics, for example, there are certain truly incorporated modes of what are nevertheless within those terms, real oppositions, that are felt and fought out. Their existence within the incorporation is recognisable by the fact that, whatever degree of internal conflict or internal variation, they do not in practice go beyond the limits of the central effective and dominant definition. This is true, for example, of the practice of parliamentary politics, though its internal oppositions are real. (Williams 2005: 39-40)

The use of incorporation here is not too dissimilar to the concept of translation from outside the semiotic space to its interior, though it implies a relation of power by the dominant centre to include elements extraneous to itself. Whether it is a residual ${ }^{3}$ or an emergent culture ${ }^{4}$, that which is not already a part of the dominant, the dominant deploys specific types of relations to incorporate the culture, either by inclusion, indifference via "malign neglect" (where we can discern a parallel with the above-mentioned mode of indifference, albeit in this latter condition, it is the purposeful lack of action that causes destruction by not interfering in an already declining process) or, in cases of severe and irreconcilable oppositions, outright destruction (Williams 2005: 43).

Tentatively, we can therefore argue that either moving into the centre or out of it, the signs and stories do not remain unscathed. In the former case, as they are incorporated into "our" space, there tend to be alterations as to whether to make the new text recognizable or even acceptable; in the latter, a case of rejection from the same space is involved. What was previously accepted and applied becomes controversial, taboo or illegal and is pushed either to the periphery where it can no longer influence the central code of the semiotic space, or simply outside of the semiotic space proper, where it becomes alien. The boundary, that membrane of translation, can in this context be imagined as a gatekeeper that selectively filters

3 "By 'residual' I mean that some experiences, meanings and values, which cannot be verified or cannot be expressed in terms of the dominant culture, are nevertheless lived and and practised on the basis of the residue - cultural as well as social - of some previous social formation" (Williams 2005: 40).

4 'By 'emergent' I mean, first, that new meanings and values, new practices, new significances and experiences, are continually being created" (Williams 2005: 41). 
in meanings and relations conducive to the maintenance of the hegemony of the centre, while those adverse to it are excluded or introduced on a marginal basis.

\section{Conclusions}

As a neologism, semiocide requires a consistent effort to establish connections with other means and forms of destruction in order to substantiate its peculiar position. This peculiarity stems from the following: any act of destruction bears a part of semiocide in it. For humans, this might be an obvious point, as we attach meaning to things - loss of an object would also mean the loss of memories and meanings attached to it. Yet even on the non-human level, destruction of the land or even changes in the habitat can prove fatal for its inhabitants, as the established semiotic connections become severed alongside the destruction on the material plane. Semiocide is not another addition to a long list of acts of killing, but an integral facet in each of its components. It needs to be underlined that the definitions we ascribe to a body in order to signify it as a 'father', a 'mother' or a 'people' are borne out of conventional means, without which all we can deduce is an entity that can only be distinguished by its physical properties. The meanings we ascribe to the specific roles individuals play in their social positions, whether it is fatherhood to a progeny or kinghood to a nation, are decipherable through the sign relations they build, adopt and maintain.

In this preliminary essay, aimed at staking out the theoretical grounds for the term, I have tried to argue for a seemingly negative set of relations in meaningmaking that are concerned more with how signs are lost, rather than with how they are produced. Losses themselves may be progenitors of meaning, in absentia, or in silence, with a total lack of signs, which in certain contexts constitutes an act of passive resistance or passive aggression and assumes a meaning of its own. We can see a related mode in political participation, or rather in the lack thereof, the absentist political praxis: in defiance, or at least in rejection, of electoral parliamentary politics in which citizens may refuse to participate in the electoral system and thereby refuse the representation of their persons in the body politic.

Though this essay dealt with and circumscribed this concept through the scope of Lotmanian semiotics in parallel with the cultural model of Raymond Williams, the range of possibilities do not end here; semiocide is potentially applicable to communicational function model by Roman Jakobson in view of the restrictions and suppressions applied to individual elements in this hexapartite structure, as well as distortion of the "functions" therein. As Maran (2013) points out, semiocide can be modelled through these components of communication, 
through violence to the addressees and addressers, disruption of the channel or corruption of the code and so on. In parallel, we can consider these acts in relation to the functions fulfilled by these components. For instance, the phatic function, ensuring the establishment, maintenance and cessation of the communicative act may be distorted to the extent that the parties cannot maintain contact either because the substrate they employ is unstable, or because the signs they employ to communicate with one another are inadequate.

Lastly, as intimated above, the imposition implied by the preliminary dichotomy between 'carelessness' and 'malevolence' requires an overhaul of the taxonomy in order to allow for acts of semiocide to be purposed for emancipation: the tacit acceptance of semiocide as a mode of negative relations that disrupts a prior order, leading to an undesirable state of affairs cannot account for occurrences in which a systemic oppression is already the norm and a change in it, through destruction of semiotic relations perpetuating it, may bring about a more emancipatory condition. In Ernesto Laclau's account of -radical- emancipation, we observe the abolishment of an old and discarded social order in favour of a new and emancipated one at such a profound discontinuity that the two orders cannot even be conceptualized upon the same ground (Laclau 2007: 4-5). Admittedly, semiocide as a singular theoretical tool may not solely affect a wholesale radical break from oppressive systems themselves, but instead, elucidate and convey particular demands and desires for systemic change by undermining and diffusing representations of oppression.

This possibility involves various ways and means of its own, such as a gradual reform or explosive/revolutionary change in a given system. Connerton's taxonomy of forgetting points at the motives from within a culture to rid itself of certain elements in order to restructure itself or to defuse and resolve its inner tensions. In history, such endeavours have required considerable readjustment of social and cultural values. Use of derogatory and dehumanizing speech is an obvious example of these conditions; social and cultural aggression crystallized and embodied in patterns of verbal or non-verbal expressions has existed throughout many societies. A similar line of argument is also present for the continued presence of cultural artefacts that commemorate dehumanizing and oppressive social relationships, couched in terms and pretexts of historical recordkeeping and remembrance. Such expressions and conventions are also 'significant', both in the semiotic sense of 'signifying', but also 'significant' in the more colloquial sense of 'bearing importance', as they maintain and sustain a particular relation of power and memory regarding whom they benefit or oppress. The mere fact that they 'signify' such relations that some sections of society would rather maintain is not an adequate motive for restraining from abolishing them. 
Could semiocide be employed in the context of such abolition? Signs, often in the form of monuments and public objects, have been known to be defaced or even completely demolished in reaction to the particular meanings they embody, as these meanings become no longer relevant or perhaps more importantly, as such meanings become explicitly at odds with the society they claim to represent. This can be viewed through the models proposed both by Lotman and Williams above: acceptable qualities at the time of a text's creation (or some other qualities that could be dismissed) undergo changes through time - for instance, undercurrents of colonialism and slave trade were amongst such elements that caused the uproar in racial equality campaigns focusing on the representations of such activities; semiocide can be viewed as iconoclasm, but from a semiotic perspective, whereby an interpretant, whose response is to impede a sign from signifying a particular object. While one may be circumspect as to what long-term prospects such interventions can achieve, they can nonetheless become symbolic moments and new signs unto themselves and engender new interpretations, in absence or in opposition to those they have replaced. Acts of destruction open up spaces for new relations to be formed.

\section{References}

Berlin, Isaiah 1969. Two concepts of liberty. In: Four Essays on Liberty. Oxford: Oxford University Press, 118-172.

Broswimmer, Franz J. 2002. Ecocide: A Short History of the Mass Extinction of Species. London: Pluto Press.

Campbell, Lyle; Muntzel, Martha C. 1989. The structural consequences of language death. In Dorian, Nancy C. (ed.), Investigating Obsolescence: Studies in Language Contraction and Death, 181-96. Cambridge: Cambridge University Press. https://doi.org/10.1017/ CBO9780511620997.016

Connerton, Paul 2008. Seven types of forgetting. Memory Studies 1(1): 59-71. https://doi. org/10.1177/1750698007083889

Crist, Eileen 2013. Ecocide and the extinction of the animal mind. In: Bekoff, Mark (ed.). Ignoring Nature No More: A Case for Compassionate Conservation. Chicago: University of Chicago Press, 45-61. https://doi.org/10.7208/chicago/9780226925363.003.0003

Doyle, Arthur Conan 2011. The adventure of the lion's mane, The Casebook of Sherlock Holmes. Middlesex: Penguin Books.

Forman, Richard T. T.; Alexander, Laurene E. 1998. Roads and their major ecological effects. Annual Review of Ecology and Systematics 29: 207-231. https://doi.org/10.1146/ annurev.ecolsys.29.1.207

Gibson, James, J. 1986. The Ecological Approach to Visual Perception. New York: Psychology Press. 
Gurevich, Aaron 1992. Historical Anthropology of the Middle Ages. (Howlett, Jana, ed.) Oxford: Polity Press.

Hobsbawm, Eric 1996. Language, culture, and national identity. Social Research 63(4): 1065-1080.

Jakobson, Roman 1964. Closing statements: Linguistics and poetics. In: Sebeok, Thomas Albert (ed.), Style in Language. Cambridge: MIT Press, 350-377.

Knight, John 1996. When timber goes wild: The desocialisation of Japanese mountain forests. In: Descola, Philippe; Pálsson, Gísli (eds.), Nature and Society: Anthropological Perspectives. London: Routledge, 221-239.

Laclau, Ernesto 2007. Emancipation(s). London: Verso Books.

Latour, Bruno 1993. We Have Never Been Modern. (Porter, Catherine, trans.) Cambridge: Harvard University Press.

Lotman, Juri 2001. Universe of the Mind: A Semiotic Theory of Culture. (Shukman, Ann, trans.; Eco, Umberto, intr.) London: I. B. Tauris Publishers.

Lowenthal, David 1985. The Past Is A Foreign Country. Cambridge: Cambridge University Press.

Maran, Timo 2013. Enchantment of the past and semiocide: Remembering Ivar Puura. Sign Systems Studies 41(1): 146-149. https://doi.org/10.12697/SSS.2013.41.1.09

Marx, Karl; Engels, Friedrich 1998[1848]. The Communist Manifesto. (Hobsbawm, Eric, intr.) London: Verso.

Nietzsche, Friedrich 2009[1887]. Genealogy of Morals. (Johnson, Ian, trans). Arlington: Richer Resources Publications.

Pálsson, Gísli 1996. Human-environmental relations: Orientalism, paternalism and communalism. In: Descola, Philippe; Pálsson, Gísli (eds.). Nature and Society: Anthropological Perspectives. London: Routledge, 63-81.

Posner, Roland 2000. Semiotic pollution: Deliberations towards an ecology of signs, Sign Systems Studies 28: 291-307.

Puura, Ivar 2013. Nature in our memory. Sign Systems Studies 41(1): 150-153. https://doi. org/10.12697/SSS.2013.41.1.10

Tulving, Endel 1993. What is episodic memory? Current Directions in Psychological Science 2(3): 67-70. https://doi.org/10.1111/1467-8721.ep10770899

Tulving, Endel 2002. Chronesthesia: Conscious awareness of subjective time. In: Stuss, Donald T.; Knight, Robert T. (eds.). Principles of Frontal Lobe Function. Oxford: Oxford University Press, 311-325. https://doi.org/10.1093/acprof:oso/9780195134971.003. 0020

Williams, Raymond 1977. Marxism and Literature. Oxford: Oxford University Press.

Williams, Raymond 1984. The Long Revolution. London: Pelican Books.

Williams, Raymond 1988. Keywords: A Vocabulary of Culture and Society. New York: Oxford University Press.

Williams, Raymond 2005. Culture and Materialism. London: Verso Books. 


\section{Семиоцид: введение в семиотику уничтожения значимости}

Цель настоящей статьи - выдвинуть и расширить понятие семиоцида, что в широком смысле означает уничтожение знаков и семиозиса. Автор приводит, отталкиваясь от статьи Ивара Пуура, где это понятие впервые появилось, концептуальные параллели и исторические примеры, расширяя возможности применения этого понятия путем критики его начальной, весьма консервативной концепции. Выдвигается точка зрения, согласно которой семиоцид может быть применен не только для описания сокрушительных потерь, но что в нем можно видеть и источник эманципаторной практики, посредством которой становится возможным подорвать существующие гегемонные и угнетающие значения и изучить новые возможности репрезентации и идентификации.

\section{Semiotsiid: sissejuhatus tähenduslikkuse hävitamise semiootikasse}

Käesoleva artikli eesmärk on tõsta esile ja laiendada semiotsiidi mõistet, mis laias laastus tähendab märkide ja semioosi hävitamist. Võttes lähtekohaks Ivar Puura artikli, milles seda mõistet käsitletakse, püütakse essees leida sellele terminile kontseptuaalseid paralleele ning ajaloolisi näiteid, laiendades mõiste kasutatavust selle algset kontseptsiooni kritiseerides. Lähtudes Puura definitsiooni algsest konservatiivsusest joonitakse artiklis alla termini mitmekesisemat mõtestamist, pooldades seisukohta, mis ei liigita semiotsiidi mitte üksnes kahetsusväärsete kaotuste kirjeldajaks, vaid näeb seda ka emantsipatoorse praktika võimaliku väljavaatena, mille kaudu saab õonestada kehtestatud, hegemoonseid ning rõhuvaid tähendusi ning uurida representatsiooni ja identiteedi uusi võimalusi. 